\title{
Vertical Diabatic Heating Structure of the MJO: Intercomparison between Recent Reanalyses and TRMM Estimates
}

\author{
Xianan Jiang, ${ }^{*}$ DuAne E. WAliser, ${ }^{+}$William S. Olson, ${ }^{\#}$ Wei-KuO TaO,${ }^{@}$ Tristan S. L'Ecuyer, ${ }^{\&}$ \\ King-FAi LI, ${ }^{*} *$ Yuk L. Yung, ${ }^{* *}$ SHOICHI SHIGe, ${ }^{++}$StePHen LANG,${ }^{@}$ AND YuKARI N. TAKAYABU ${ }^{\# \#}$ \\ * Joint Institute for Regional Earth System Science and Engineering, University of California, Los Angeles, Los Angeles, and \\ Jet Propulsion Laboratory, California Institute of Technology, Pasadena, California \\ ${ }^{+}$Jet Propulsion Laboratory, California Institute of Technology, Pasadena, California \\ \# Joint Center for Earth Systems Technology, University of Maryland, Baltimore County, Baltimore, Maryland \\ ${ }^{@}$ Laboratory for Atmospheres, NASA Goddard Space Flight Center, Greenbelt, Maryland \\ ${ }^{\&}$ Department of Atmospheric Science, Colorado State University, Fort Collins, Colorado \\ ** Division of Geological and Planetary Sciences, California Institute of Technology, Pasadena, California \\ ${ }^{++}$Graduate School of Science, Kyoto University, Kyoto, Japan \\ \#\# Atmosphere and Ocean Research Institute, The University of Tokyo, Tokyo, Japan
}

(Manuscript received 23 September 2010, in final form 5 April 2011)

\begin{abstract}
Capitalizing on recently released reanalysis datasets and diabatic heating estimates based on Tropical Rainfall Measuring Mission (TRMM), the authors have conducted a composite analysis of vertical anomalous heating structures associated with the Madden-Julian oscillation (MJO). Because diabatic heating lies at the heart of prevailing MJO theories, the intention of this effort is to provide new insights into the fundamental physics of the MJO. However, some discrepancies in the composite vertical MJO heating profiles are noted among the datasets, particularly between three reanalyses and three TRMM estimates. A westward tilting with altitude in the vertical heating structure of the MJO is clearly evident during its eastward propagation based on three reanalysis datasets, which is particularly pronounced when the MJO migrates from the equatorial eastern Indian Ocean (EEIO) to the western Pacific (WP). In contrast, this vertical tilt in heating structure is not readily seen in the three TRMM products. Moreover, a transition from a shallow to deep heating structure associated with the MJO is clearly evident in a pressure-time plot over both the EEIO and WP in three reanalysis datasets. Although this vertical heating structure transition is detectable over the WP in two TRMM products, it is weakly defined in another dataset over the WP and in all three TRMM datasets over the EEIO.

The vertical structures of radiative heating $Q_{R}$ associated with the MJO are also analyzed based on TRMM and two reanalysis datasets. A westward vertical tilt in $Q_{R}$ is apparent in all these datasets: that is, the lowlevel $Q_{R}$ is largely in phase of convection, whereas $Q_{R}$ in the upper troposphere lags the maximum convection. The results also suggest a potentially important role of radiative heating for the MJO, particularly over the Indian Ocean. Caveats in heating estimates based on both the reanalysis datasets and TRMM are briefly discussed.
\end{abstract}

\section{Introduction}

Diabatic heating is the ultimate energy source for driving the atmospheric circulation. In the tropics, latent heat release associated with deep convection is the dominant component of total diabatic heating. The heating induced

Corresponding author address: Dr. Xianan Jiang, Jet Propulsion Laboratory, MS 183-501, 4800 Oak Grove Drive, Pasadena, CA 91109.

E-mail: xianan@jifresse.ucla.edu large-scale circulation can further influence convection by modifying atmospheric instability through redistributing the localized latent heat and moisture or through dynamical lifting by low-level convergence. Because of this interactive process between convection and circulation, tropical climate/weather systems are often organized on selected space and time scales, rather than in a random manner. For example, the 30-60-day period MaddenJulian oscillation (MJO; Madden and Julian 1971, 1994) is a dominant subseasonal mode of tropical atmospheric variability. Because it exerts significant modulation on 
global climate/weather systems [see reviews by Lau and Waliser (2005); Zhang (2005), and references therein], the $\mathrm{MJO}$ has received extensive attention in recent decades.

The MJO is largely considered to result from the aforementioned interaction between convection and large-scale circulation. To interpret the essential observed features of the MJO, prevailing MJO theories emphasize instability arising from various feedbacks between diabatic heating and large-scale dynamics, for example, from coupling between convective heating in the free atmosphere and Kelvin waves [e.g., wave conditional instability of second kind (CISK); Lau and Peng 1987; Chang and Lim 1988] or from latent heating in the planetary boundary layer (PBL) by frictional moisture convergence (Wang and Rui 1990; Hendon and Salby 1994; Maloney and Hartmann 1998). In addition, the importance of high-order vertical heating modes for MJO instability is emphasized (e.g., "stratiform instability"; Mapes 2000). Besides convective heating, the role of radiative heating for the MJO is also proposed based on observations (e.g., Lin and Mapes 2004; Stephens et al. 2004; Masunaga et al. 2005) and numerical studies (e.g., Lee et al. 2001; Raymond 2001; Sobel and Gildor 2003). For a thorough review of the MJO theories, readers are referred to Wang (2005).

Despite recent progress in understanding MJO physics, the capability of current general circulation models (GCMs) to simulate the MJO remains limited (e.g., Slingo et al. 1996, 2005; Lin et al. 2006; Kim et al. 2009). Useful predictive skill for the MJO has generally been limited to only 1-2 weeks (e.g., Waliser et al. 2006; Jiang et al. 2008), in contrast to its potential predictability of about 2-4 weeks (Waliser 2006). Therefore, continued improvement in our fundamental understanding of the MJO is still critical. Because diabatic heating lies at the heart of the main MJO theories as discussed above, a comprehensive characterization of the vertical heating structure of the MJO would be of considerable value in elucidating its essential physics.

Previous attempts in exploring the vertical heating structure of the MJO largely relied on sounding observations from field experiments: for example, the Tropical Ocean Global Atmosphere Coupled Ocean-Atmosphere Response Experiment (TOGA COARE; Webster and Lukas 1992). Based on TOGA COARE observations, a vertical tilt of the heating profile associated with the MJO was illustrated (e.g., Lin et al. 2004; Kiladis et al. 2005), with low-level heating preceding MJO deep convection, deep heating at the peak of convection, and upperlevel heating following the heaviest MJO rainfall. This vertical transition in MJO heating structure is consistent with cloud morphology during the MJO evolution as revealed by many observational studies, with shallow cumuli/congestus clouds at the leading edge of the MJO, followed by deep convective clouds and then high stratiform anvil clouds (e.g., Johnson et al. 1999; Kikuchi and Takayabu 2004; Kiladis et al. 2005; Mapes et al. 2006; Chen and Del Genio 2009; Khouider and Majda 2008; Tromeur and Rossow 2010). Moreover, prior to the onset of MJO convection, accompanying shallow heating and congestus clouds, PBL convergence (e.g., Sperber 2003; Kiladis et al. 2005) and moisture accumulation (Kemball-Cook and Weare 2001; Sperber 2003; Kiladis et al. 2005; Tian et al. 2006, 2010) are observed. All these observational evidences may signify the essential role of the coupling between the shallow latent heat release in congestus clouds and circulation in the PBL in effectively destabilizing MJO deep convection.

The potential importance of shallow heating prior to MJO deep convection is supported by idealized model or GCM simulations (e.g., Wu 2003; Zhang and $\mathrm{Mu}$ 2005; Benedict and Randall 2009; Li et al. 2009; Zhang and Song 2009). On the other hand, the importance of the stratiform heating component for the MJO is also emphasized in other GCM studies (e.g., Fu and Wang 2009; Seo and Wang 2010). Nevertheless, the vertical tilting structure in the MJO heating field as derived from TOGA COARE was not evident in recent sounding observations during the Mirai Indian Ocean Cruise for the Study of the MJO Onset (MISMO) field experiment (Katsumata et al. 2009). This difference could be ascribed to different observational sites [i.e., TOGA COARE over the western Pacific (WP) and MISMO over the central Indian Ocean], or it could also be MJO case dependent because only one or two MJO events were observed during these field campaigns.

In recent years, there have been continuous efforts by several research groups in estimating 3D atmospheric diabatic heating profiles based on the Tropical Rainfall Measuring Mission (TRMM; Tao et al. 2006). Although general characteristics of heating associated with tropical convection based on these TRMM heating products have been explored (e.g., Chan and Nigam 2009; Hagos et al. 2010; Takayabu et al. 2010; Elsaesser et al. 2010), initial studies on the MJO heating structure employed a short period of these TRMM datasets (Jiang et al. 2009; Lau and Wu 2010) or were based on earlier versions of these estimates (Morita et al. 2006). By conducting a composite analysis based on one TRMM heating product for a period of about $3 \mathrm{yr}$, Lau and $\mathrm{Wu}$ (2010) identified a shallow heating mode accompanying prevailing warm rain prior to the MJO deep heating over the western Pacific. This shallow heating component of the MJO, however, is not clearly evident in the composite study for MJO events over both Indian and western Pacific Oceans by Morita et al. (2006) based on an earlier version of another TRMM estimate and in the case study by Jiang et al. (2009) 
over the Indian Ocean during the winter of 1998/99 based on two TRMM products as well as the 40-yr European Centre for Medium-Range Weather Forecasts (ECMWF) Re-Analysis (ERA-40) and forecast.

By conducting an empirical orthogonal function (EOF) analysis of vertical latent heat profiles over various longitudes along the equatorial belt based on four recently updated TRMM products, recent work by Zhang et al. (2010) illustrated that, regardless of longitudes along the equator, latent heat vertical structures are dominated by two components, one deep with its peak above the melting level and one shallow with its peak below. Zhang et al. (2010) further examined evolution of these two heating components associated with the MJO and found that the four TRMM datasets agree well in their deep components but not in their shallow components and in the phase relations between the deep and shallow components.

In the light of the inconsistency in previous observational studies of the MJO heating structure, in this study we attempted to comprehensively characterize the vertical MJO heating profiles by conducting a composite analysis based on a widely used MJO index (i.e., a realtime multivariate MJO index; Wheeler and Hendon 2004), with three TRMM heating products and three recently released high-quality reanalysis datasets. During the course of this study, however, we noticed that a similar study was being conducted by Ling and Zhang (2011, hereafter LZ11. By employing a same MJO index, LZ11 largely discussed the composite verticaltemporal heating profiles of the MJO over the Indian Ocean, Maritime Continent, and western Pacific. To avoid overlap, in the present study we mainly focus on the composite MJO heating structures on a verticallongitudinal cross section during the MJO evolution. We also present time-pressure MJO heating profiles over the Indian and western Pacific Oceans averaged over a tropical belt of $10^{\circ} \mathrm{S}-10^{\circ} \mathrm{N}$ instead of the belt of $15^{\circ} \mathrm{S}-$ $15^{\circ} \mathrm{N}$ used in LZ11. This serves as a sensitivity test of vertical heating structures with latitude bands. Moreover, the vertical structures of radiative heating $Q_{R}$ associated with the MJO are also discussed in this study.

\section{Data and approach}

Daily 3D fields of apparent heating $Q_{1}$ (Yanai et al. 1973) are analyzed from three reanalysis datasets-the ECMWF ERA-Interim (Simmons et al. 2006), the National Aeronautics and Space Administration (NASA) Modern-Era Retrospective Analysis for Research and Applications (MERRA; Bosilovich et al. 2006), and the National Oceanic and Atmospheric Administration (NOAA) Climate Forecast System Reanalysis (CFS-R;
Saha et al. 2010) - and three TRMM products based on "trained" radiometer heating (TRAIN; Grecu and Olson 2006; Grecu et al. 2009), convective-stratiform heating (CSH; Tao et al. 2010), and spectral latent heating (SLH; Shige et al. 2004, 2007, 2008, 2009) algorithms, respectively. Radiative heating $Q_{R}$ from TRMM estimates based on the Hydrologic Cycle and Earth's Radiation Budget (HERB) algorithm (TRMM $Q_{R}$; L'Ecuyer and Stephens 2003, 2007; L'Ecuyer and McGarragh 2010) as well as from MERRA and CFS-R are also analyzed. Techniques in generating these datasets, as well as horizontal and vertical resolutions of these products, can be found in Table 1 and references therein. Note that $Q_{1}$ fields based on ERA-Interim are derived from 3D wind and temperature fields by applying residual budget analysis following Yanai et al. (1973), whereas they are explicitly calculated terms in the models employed for MERRA and CFS-R. Rainfall fields based on the three reanalysis datasets are also analyzed to help understand the differences in heating profiles between reanalyses and TRMM estimates. These rainfall fields are produced by cumulus and large-scale cloud schemes from the reanalysis models with constraints from observed dynamical/thermodynamical variables. Also note that the heating variable provided by the TRMM SLH algorithm is $Q_{1}-Q_{R}$ instead of $Q_{1}$ in other datasets.

Daily rainfall patterns are derived from 3-hourly TRMM 3B42 estimates (Huffman et al. 2007) to illustrate the evolution of convection associated with the MJO. TRMM 3B42 rainfall is a global precipitation product based on multisatellite and rain gauge analysis. The MJO is defined by the real-time multivariate MJO (RMM) index following Wheeler and Hendon (2004), which is based on an EOF analysis of the combined fields of equatorially averaged 850 - and $200-\mathrm{hPa}$ zonal wind and NOAA outgoing longwave radiation (OLR). The two daily $\mathrm{RMM}$ indices, $\mathrm{RMM}_{1}$ and $\mathrm{RMM}_{2}$, are used to determine the MJO phases (ranging from 1 to 8 ) and amplitudes. Composite analysis of both heating and rainfall can then be achieved by averaging these fields over each MJO phase based on selected strong MJO events $\left(\mathrm{RMM}_{1}^{2}+\mathrm{RMM}_{2}^{2} \geq 1\right)$ during boreal winter (November-April) from 1998 to 2007/08 (see Table 1). Prior to the composite, all daily heating and rainfall fields but those from the TRMM CSH and SLH algorithms are subject to bandpass filtering to retain the periods of 20-90 days. For CSH and SLH heating based on TRMM Precipitation Radar (PR), because of large amounts of missing data in daily fields, only a 5-day running mean is applied after removal of the climatological annual cycle. A test based on TRAIN $Q_{1}$ shows that both methods in deriving the anomalous fields produce similar composite structures due to relatively large 


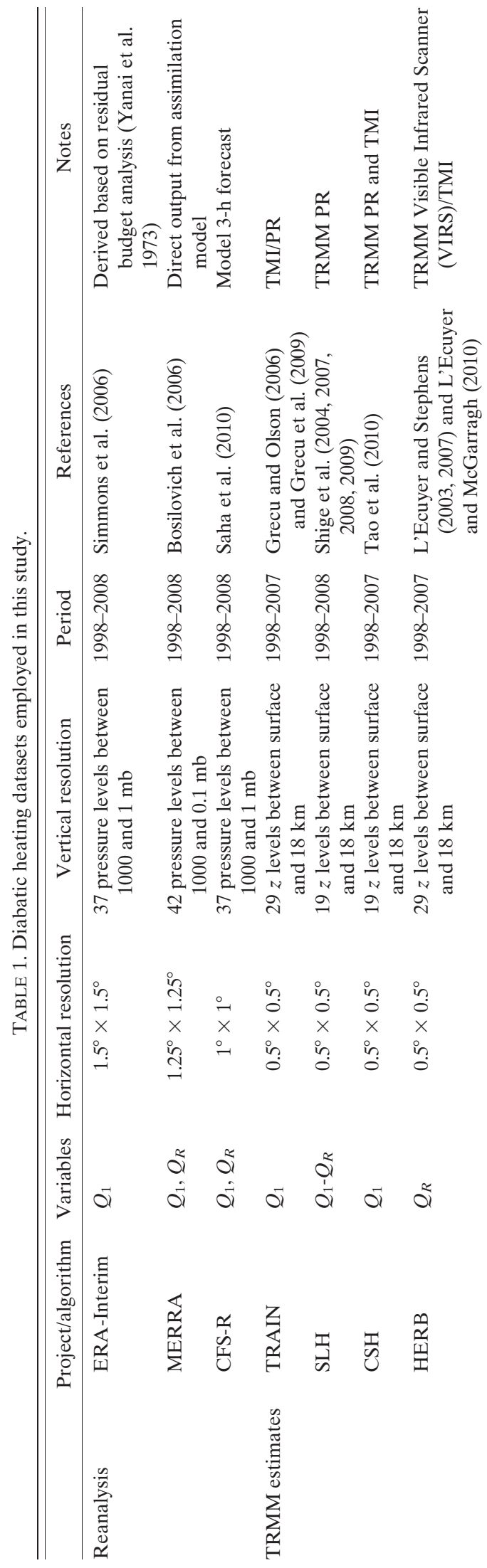

sampling sizes $(\sim 140)$, although smoother patterns and relatively weaker amplitudes are apparent in the composite results based on time-filtered fields.

\section{Results}

\section{a. MJO diabatic heating profiles}

Figure 1 illustrates composite pressure-longitude profiles of anomalous $Q_{1}$ (shading) along the equator during MJO phases 1-8 based on three reanalysis datasets. Black curves in each panel represent the associated longitudinal distribution of composite TRMM 3B42 rainfall anomalies, whereas red curves represent rainfall profiles based on corresponding reanalysis datasets. In general, the rainfall evolution based on each reanalysis during the MJO cycle is in agreement with the TRMM 3B42. Note that a latitude band from $10^{\circ} \mathrm{S}$ to $10^{\circ} \mathrm{N}$ is used to represent the equatorial belts in all of the following figures if not otherwise mentioned. At MJO phase 1, enhanced rainfall anomalies begin to form over the western Indian Ocean and then intensify while slowly propagating eastward. At phase 3, enhanced convection is located over the equatorial eastern Indian Ocean (EEIO) and crosses the Maritime Continent during phase 4. It then continues to slowly migrate eastward and gradually damps near the date line after phase 7. In accord with the evolution of rainfall, the vertical $Q_{1}$ profiles associated with the MJO based on three reanalyses are largely similar, including consistent eastward propagation and a maximum heating rate near $450 \mathrm{hPa}$. A noteworthy feature in $Q_{1}$ profiles based on all three datasets is the marked westward tilting with altitude during the eastward propagation. Low-level heating appears to the east side of the deep heating structure (i.e., it leads the MJO deep convection). Meanwhile, a trailing heating structure appears in the upper troposphere to the west of the convection center. This vertical tilting structure is most pronounced around phase 3 , when the convection migrates from the EEIO to the WP.

We also note differences in rainfall profiles between TRMM 3B42 and reanalysis datasets. The rainfall amplitude based on each reanalysis dataset is generally weaker than its TRMM counterpart. During the period when the shallow heating component is most evident (e.g., at phase 3), a second rainfall peak is detected to the east of the rainfall maximum in ERA-Interim, which corresponds well to the shallow heating component. Additionally, during the MJO transition from the EEIO to WP at phase 4, two enhanced rainfall peaks are observed in TRMM and two reanalyses datasets, MERRA and CFS-R, one over the EEIO and another over the WP; instead, only the rainfall peak over the WP is evident in ERA-Interim. 


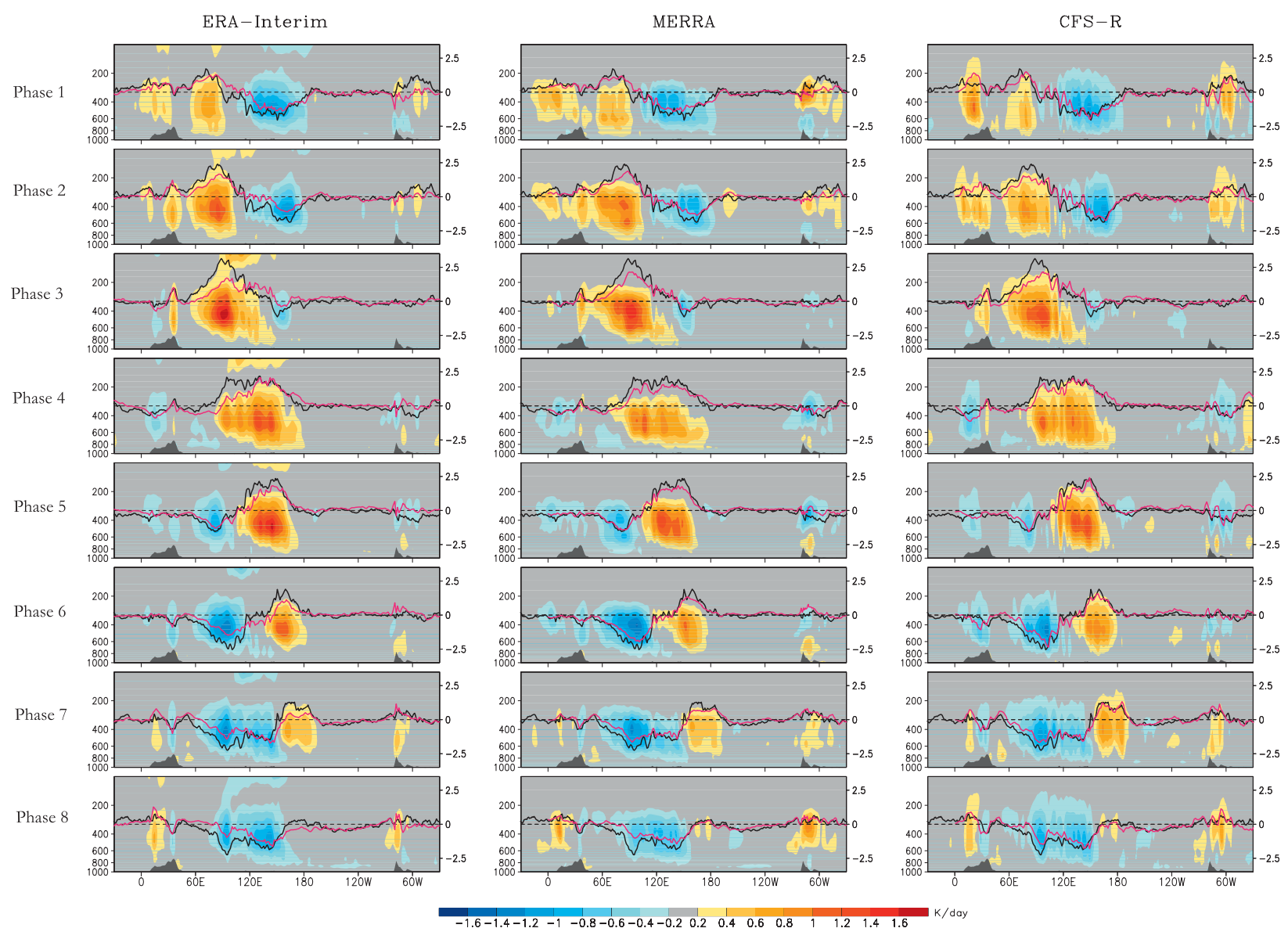

FIG. 1. Longitude-pressure profiles of composite anomalous diabatic heating $Q_{1}$ (shaded; see color bar; units are K day ${ }^{-1}$ ) during MJO evolution (phases 1-8) based on three reanalysis datasets, (a) ERA-Interim, (b) MERRA, and (c) CFS-R. Black (red) curves denote longitudinal distribution of anomalous rainfall (scales on right $y$ axis; units are $\mathrm{mm} \mathrm{day}^{-1}$ ) based on TRMM $3 \mathrm{~B} 42$ (each reanalysis dataset) at corresponding $\mathrm{MJO}$ phase. Both heating and rainfall fields are averaged over $10^{\circ} \mathrm{S}-10^{\circ} \mathrm{N}$.

Similar pressure-longitude heating profiles of the MJO based on three TRMM products are displayed in Fig. 2. Note that the rainfall fields used to produce these three TRMM heating products are slightly different. The TRMM Microwave Imager (TMI) rainfall is used by TRAIN estimates, although this TMI algorithm is calibrated by TRMM PR rainfall, whereas SLH utilizes TRMM PR (2A25) rainfall and the CSH algorithm employs rainfall fields from TRMM 3 G68 version, which combines both TMI and PR information. For simplicity, in Fig. 2 we only display the longitudinal rainfall profiles during each MJO phase based on the standard TRMM 3B42 product. All three TRMM versions exhibit largely similar composite rainfall profiles associated with the MJO. In Fig. 2, although eastward propagation of heating anomalies is also evident, notable differences between TRMM estimates and reanalyses exist. Although the TRAIN heating exhibits a stronger amplitude than those in three reanalysis datasets, the SLH and
CSH amplitudes are weaker. Meanwhile, the westward tilt in heating structure during the MJO evolution as evident in Fig. 1 is not as clear in the three TRMM datasets.

Figure 3 demonstrates vertical-temporal anomalous heating profiles (shaded) based on six datasets over the WP and EEIO. The time (MJO phases) in the $x$ axis of each panel runs from right to left so that these plots also mimic longitude-height cross sections for an eastwardmoving system. The black curve in each panel denotes evolution of TRMM rainfall anomalies (scales on right). Figure 3 shows that, over the WP, the heating profiles based on three reanalyses exhibit a similar vertical tilting structure (Figs. 3a-c), although the ERA-Interim exhibits stronger heating signal in the upper troposphere. The low-level heating below $800 \mathrm{hPa}$ appears around phase 3 and peaks at phase 4 prior to the maximum MJO convection at phase 5. Meanwhile, a maximum heating near $450 \mathrm{hPa}$ after phase 5 is discerned in 
TRAIN
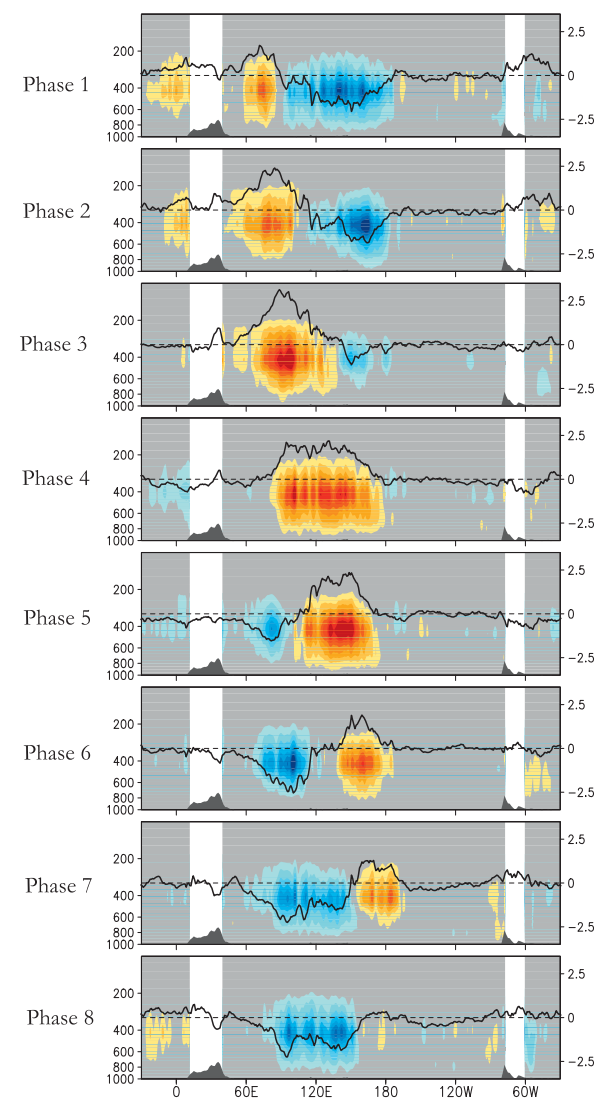

SLH
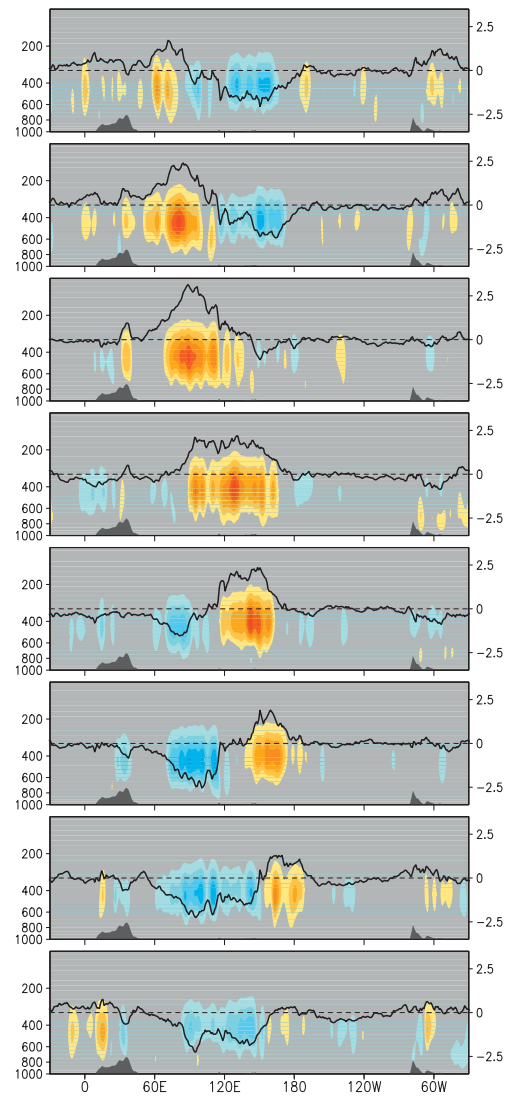

$\mathrm{CSH}$
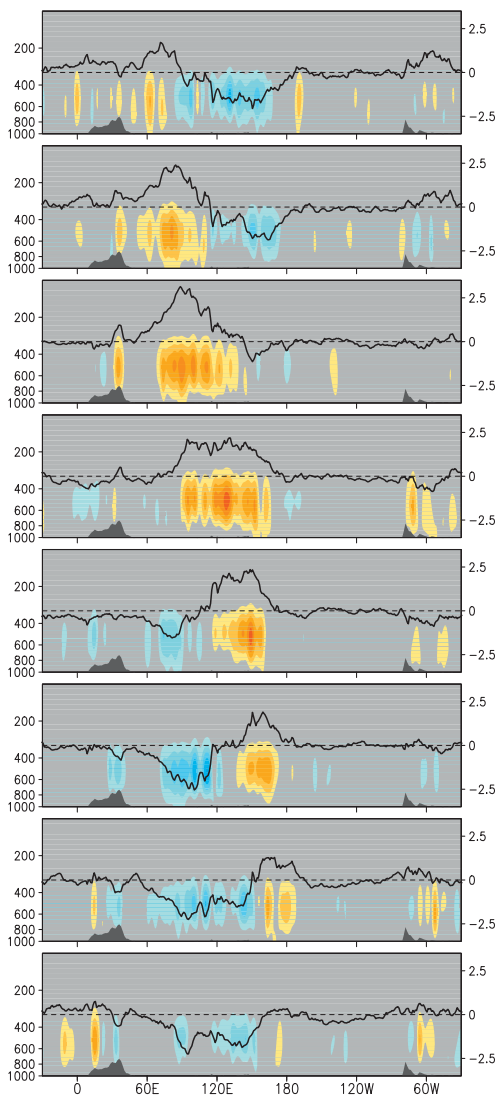

FIG. 2. As in Fig. 1, but for $Q_{1}$ profiles (except for SLH, which is $Q_{1}-Q_{R}$ ) based on three TRMM estimates.

all three reanalysis datasets. In addition to the upperlevel heating maximum, a second peak around $600 \mathrm{hPa}$ is also apparent in MERRA (Fig. 3b). In contrast, the vertical tilt in the heating profiles varies among the three TRMM products. Although the tilt is evident in $\mathrm{CSH}$, the heating does not extend as high in the upper troposphere as in other datasets (Fig. 3f). Although the lead of shallow heating to maximum convection is also discerned in the SLH heating $\left(Q_{1}-Q_{R}\right)$ profile, it has much weaker amplitude below $600 \mathrm{hPa}$ (Fig. 3e). This could be partially due to the exclusion of $Q_{R}$ in this product, because low-level anomalous $Q_{R}$ is largely in phase with MJO convection, as will shown later. Meanwhile, a rather weak tilt is seen in TRAIN profile (Fig. 3d); instead of a slight lag to maximum convection in other datasets, the upper-level heating maximum is largely in phase with convection in TRAIN.

Over the EEIO, the transition from a shallow to deep heating structure during the MJO evolution is again evident based on three reanalysis datasets (Figs. 3g-i). However, among these datasets, some differences in the upper-level heating profiles are noticed between the
EEIO and WP. Although the heating maxima around $400 \mathrm{hPa}$ lag the rainfall peaks over the WP, they appear at the peaks of MJO convection over the EEIO (cf. Figs. $3 a-c$ with Figs. $3 g-i)$. The vertical transition from shallow to deep heating structure as seen in the reanalyses is not readily apparent in all three TRMM-based datasets over this region (Figs. 3j-1).

Similar composite vertical-time heating profiles of the MJO based on the same reanalyses and TRMM estimates as in Fig. 3 were illustrated in LZ11 over the EEIO, Maritime Continent, and WP (their Fig. 7). Because the results over the Maritime Continent are largely similar to the WP based on our analysis, only profiles over the EEIO and WP are shown in Fig. 3. Although both this present study and LZ11 indicate discrepancies in vertical heating profiles between reanalyses and TRMM estimates, differences between these two studies are also noted regarding the consistency among reanalysis datasets. As illustrated by Fig. 3, our analysis suggests that the composite heating profiles among three reanalysis datasets agree well over both the EEIO and WP regions (also over the Maritime Continent; figure not shown); namely, 
Western Pacific (150-160E; 10S-10N)

a) ERA-Interim

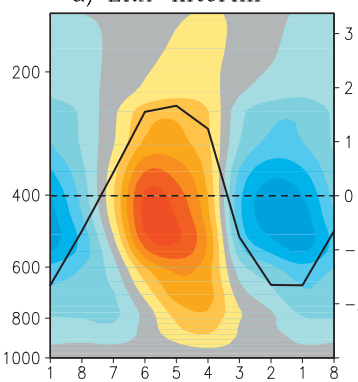

d) TRAIN

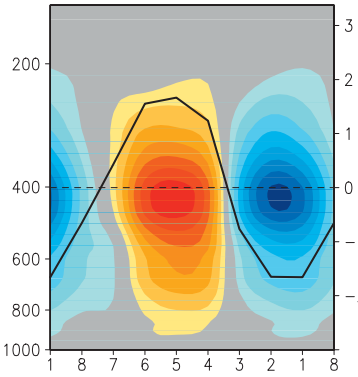

b) MERRA

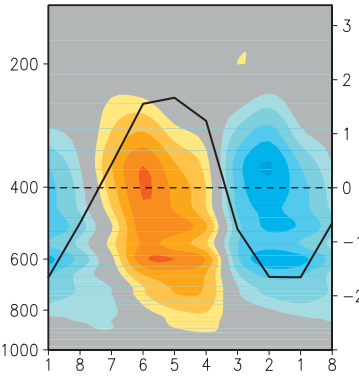

e) $\mathrm{SLH}$

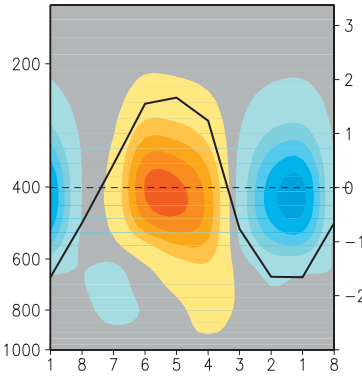

c) $\mathrm{CFS}-\mathrm{R}$

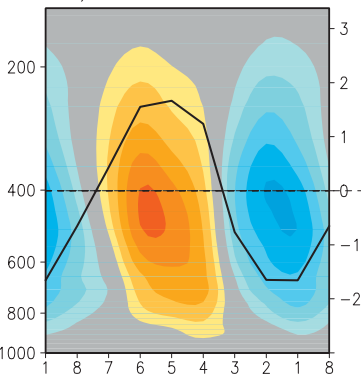

f) $\mathrm{CSH}$

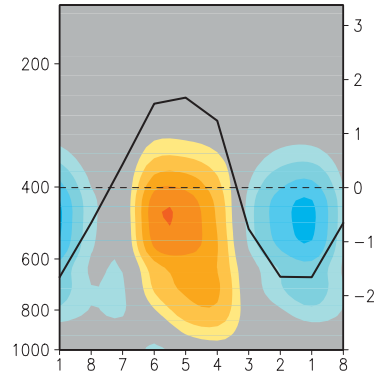

Indian Ocean (80-90E; 10S-10N)

g) ERA-Interim

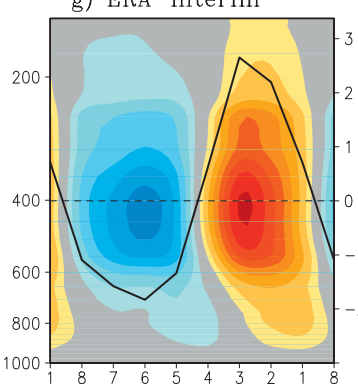

j) TRAIN

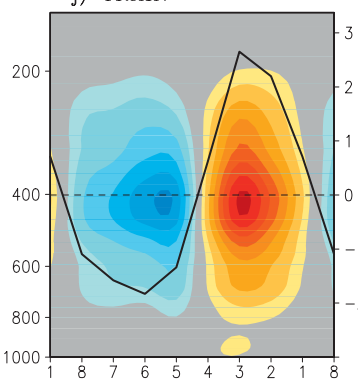

h) MERRA

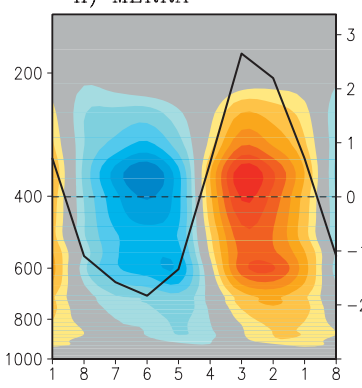

k) SLH

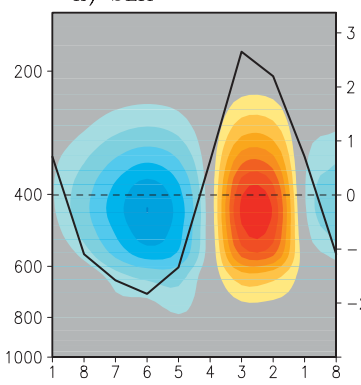

i) $\mathrm{CFS}-\mathrm{R}$

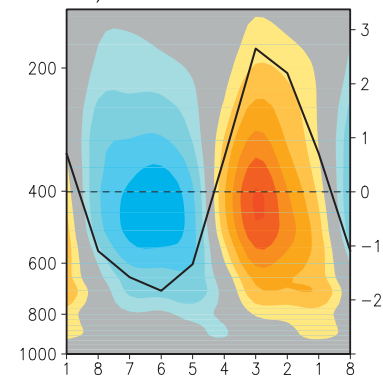

1) $\mathrm{CSH}$

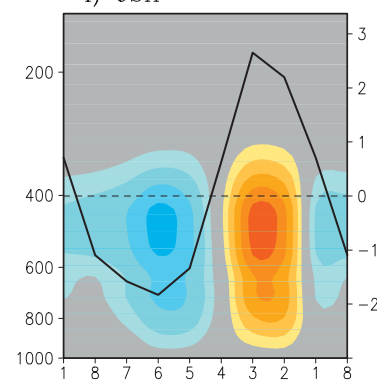

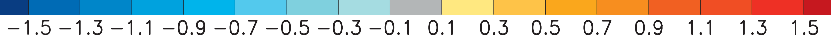

K/day

FIG. 3. Vertical-temporal (MJO phases) evolution of anomalous heating $Q_{1}$ or $Q_{1}-Q_{R}$ for TRMM SLH (shaded; units are $\mathrm{K}$ day $^{-1}$ ) over (a)-(f) the WP $\left(150^{\circ}-160^{\circ} \mathrm{E}\right)$ and (g) $-(\mathrm{l})$ the EEIO $\left(80^{\circ}-90^{\circ} \mathrm{E}\right)$ based on three reanalysis datasets and three TRMM estimates. The back curves represent evolution of TRMM 3B42 rainfall anomalies (see scales right $y$ axis with units of $\mathrm{mm}$ day $\left.^{-1}\right)$. All variables are averaged over $10^{\circ} \mathrm{S}-10^{\circ} \mathrm{N}$. 
shallow heating leading the deep mode associated with the MJO is clearly apparent in all three reanalyses over both the EEIO and WP. In contrast, discrepancies among the reanalyses were reported in LZ11. It was shown in LZ11 that, although MJO heating profiles in all these reanalyses exhibit a westward tilting over the WP, opposite vertical tilting directions are found over the EEIO and Maritime Continent in ERA-Interim and CSH but not in MERRA.

To understand the above disagreement between the present study and LZ11, several differences in detailed composite techniques between these two studies are worth mentioning. First, a 7-day running mean was applied on the original daily RMM time series in LZ11, whereas the original RMM indices are used for composites in this study. Second, prior to composite analysis, anomalous heating fields in LZ11 were obtained by a 7-day running mean after removal of the climatological annual cycle and interannual signals associated with El Niño. In this study, we applied 20-90-day bandpass filtering to all three reanalysis heating datasets after the removal of the climatological annual cycle. Third, a latitude band of $15^{\circ} \mathrm{S}-15^{\circ} \mathrm{N}$ was adopted when conducting averages over the equatorial belt in LZ11, whereas a band of $10^{\circ} \mathrm{S}-10^{\circ} \mathrm{N}$ is used in this study. Fourth, single grid points near longitudes at $90^{\circ}, 120^{\circ}$, and $150^{\circ} \mathrm{E}$ were taken to represent the EEIO, the Maritime Continent, and the WP, respectively, in LZ11. Instead, we take average over longitude bands of $85^{\circ}-95^{\circ} \mathrm{E}$ and $145^{\circ}-155^{\circ} \mathrm{E}$ to represent the EEIO and WP.

Our sensitivity tests suggest that the different latitude band (i.e., $10^{\circ} \mathrm{S}-10^{\circ} \mathrm{N}$ in this study versus $15^{\circ} \mathrm{S}-15^{\circ} \mathrm{N}$ in LZ11) is the critical factor leading to the vertical heating profile differences between these two studies. A similar figure as Fig. 3 but averaged over $15^{\circ} \mathrm{S}-15^{\circ} \mathrm{N}$ shows largely consistent results with Fig. 7 of LZ11. Further examination suggests that the disagreement in results over the two latitude bands is largely from $15^{\circ}$ to $10^{\circ} \mathrm{S}$, specifically from a region between coastal northwest Australia and Java Island (figure not shown). The maximum anomalous rainfall over this region is attained during MJO phases 5 and 6; meanwhile, the bulk MJO convection near the equator has arrived in the western Pacific [see Wheeler and Hendon (2004), their Fig. 8]. Therefore, the heating profiles averaged over a latitudinal band of $15^{\circ} \mathrm{S}-15^{\circ} \mathrm{N}$ near the Maritime Continent longitudes will capture a mixed structure associated with both the MJO convective signals near the equator and over the region near the northwestern Australian coast. Further investigation is needed regarding the physics responsible for the local enhanced rainfall anomalies over the region near the northwest Australian coast during the MJO phases 5 and 6.
To more clearly illustrate the differences in MJO vertical heating structures, particularly between the reanalyses and TRMM estimates, Fig. 4 shows horizontal heating distributions (shaded) at 400,650, and $800 \mathrm{hPa}$, respectively, from the six datasets at MJO phase 3. As previously mentioned, the heating profile vertical tilt on a pressure-longitude plane is most obvious during this period in three reanalyses, whereas it is not obviously evident in the TRMM products. Contours superimposed on shading in each panel in Fig. 4 represent the TRMM 3B42 surface rainfall pattern at the same MJO phase. Maximum MJO convection is found over the EEIO near $90^{\circ} \mathrm{E}$, with two off-equatorial centers on both sides. At $400 \mathrm{hPa}$, where the vertical maximum $Q_{1}$ is generally observed (see Fig. 1), the $Q_{1}$ patterns are largely similar among these datasets and are in accord with the surface rainfall pattern, albeit with differences in $Q_{1}$ amplitudes. The $Q_{1}$ patterns at $650 \mathrm{hPa}$ are also largely in agreement with each other among these datasets (Fig. 4b).

At $800 \mathrm{hPa}$, although the three reanalysis $Q_{1}$ patterns largely resemble one another, significant differences are noted between reanalyses and TRMM estimates in both $Q_{1}$ amplitude and distribution. In the three reanalyses, although positive $Q_{1}$ anomalies are evident over the Indian Ocean, the strongest $Q_{1}$ anomalies are found over the Maritime Continent (i.e., to the east of the MJO convection center), which is consistent with the verticallongitudinal profiles at phase 3, as illustrated in Fig. 1. In contrast, the strong shallow heating over the Maritime Continent are absent in three TRMM estimates. Maximum heating anomalies are still located within the convection center over the Indian Ocean in TRAIN and CSH. Meanwhile, SLH exhibits weak cooling anomalies at $800 \mathrm{hPa}$ in the MJO center over the Indian Ocean, shifting maximum heating along equatorial belts to the east of maximum MJO convection, although the heating amplitude is much weaker than that based on reanalyses.

To illustrate how physical processes couple with the shallow heating to the east of MJO convection in the reanalyses, Fig. 5 shows pressure-longitude cross sections of several dynamical and thermodynamical fields at MJO phase 3 based on ERA-Interim. As in Fig. 1, Fig. 5a shows the vertical-longitudinal $Q_{1}$ profile along the equatorial region with corresponding rainfall profiles displayed in Figs. 5e,f. Again, the center of deep heating is located near $90^{\circ} \mathrm{E}$ and is consistent with the maximum rainfall. Meanwhile, a shallow heating component is found between $120^{\circ}$ and $150^{\circ} \mathrm{E}$, corresponding with a secondary rainfall peak. Figures $5 b-d$ present corresponding vertical profiles of cloud water content, divergence, and specific humidity fields, respectively, at the same MJO phase. The maximum MJO $Q_{1}$ and rainfall over the Indian Ocean are consistent with enhanced 

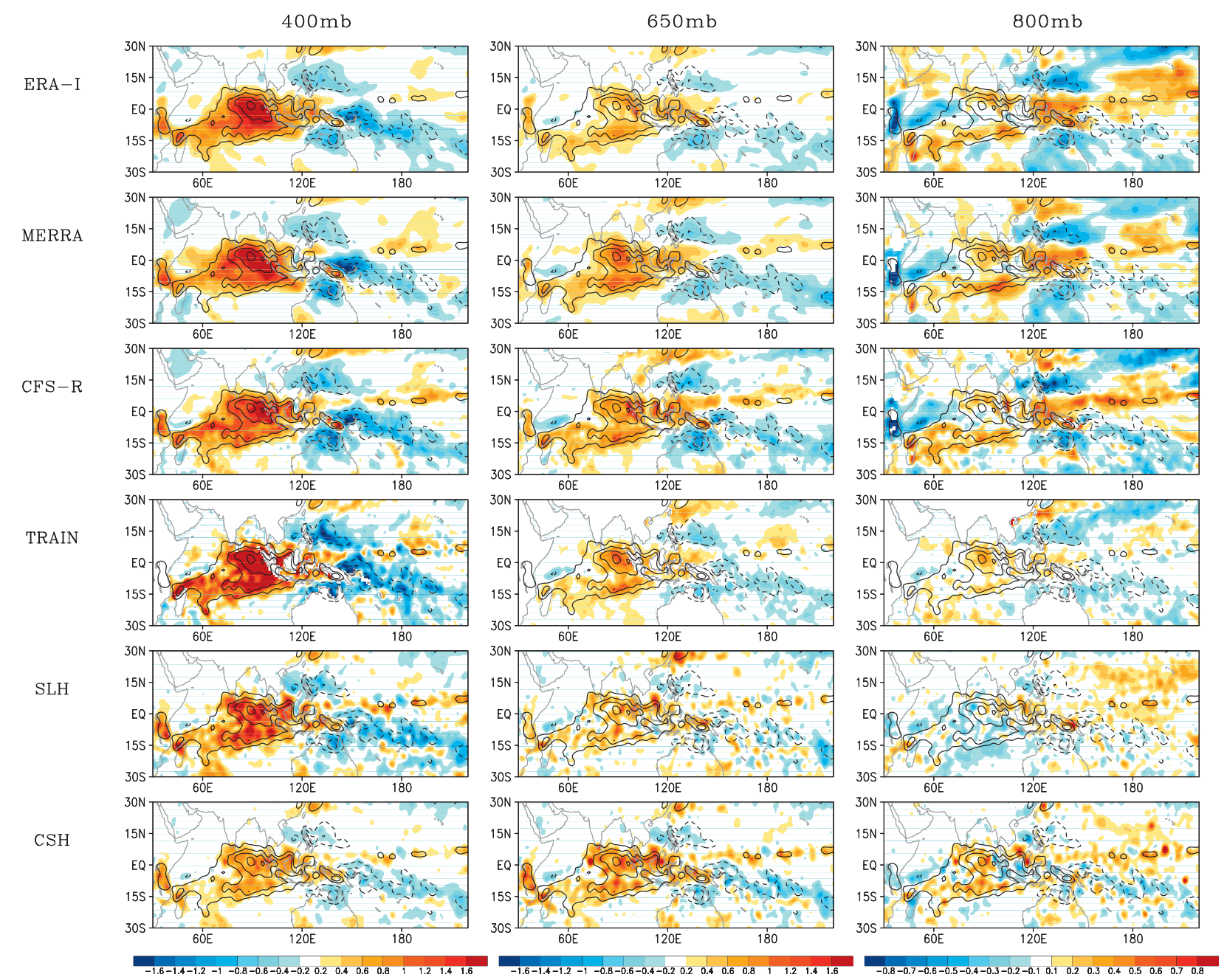

FIG. 4. Shading shows horizontal distribution of anomalous heating $Q_{1}\left(Q_{1}-Q_{R}\right.$ for SLH) at (left) 400 , (middle) 650 , and (right) $800 \mathrm{hPa}$ at MJO phase 3. See color bar below for scales at each vertical level with units of $\mathrm{K} \mathrm{day}^{-1}$. Contours show surface rainfall distribution at phase 3 based on TRMM 3B42. Solid (dashed) curves denote enhanced (suppressed) rainfall with the first solid (dashed) contour for 1 $(-1) \mathrm{mm} \mathrm{day}^{-1}$ and an interval of $1 \mathrm{~mm} \mathrm{day}^{-1}$.

cloud water, specific humidity, and lower-level (upper level) convergence (divergence). Particularly interesting is that the shallow heating ahead of the MJO convection between $120^{\circ}$ and $150^{\circ} \mathrm{E}$ is consistent with PBL convergence (Fig. 5c) and enhanced moisture (Fig. 5d) and cloud water (Fig. 5b) in the lower troposphere. As mentioned in the introduction, PBL convergence, enhanced moisture, and shallow clouds at the leading edge of the MJO deep convection have been widely reported in previous observational studies, signifying a preconditioning process for the MJO.

Therefore, the results illustrated in Figs. 4 and 5 may suggest that the missing part in the shallow heating component in the three TRMM products, which is most apparent over the WP during MJO phase 3, could represent an important process for the MJO preconditioning. It has been reported that, because of the limitation in the sensitivity of PR, the TRMM-based rainfall product could underestimate the contribution of light rain and/or small, isolated rain events over regions where shallow clouds dominate (e.g., Short and Nakamura 2000; Berg et al. 2010). It is thus expected that light rain from shallow clouds ahead of the MJO deep convection could be underestimated in TRMM rainfall. Because the TRMM-based latent heat retrieval algorithms are determined by precipitation rate and rain types with aids of lookup tables generated by cloud resolving models, the shallow heating component could be underestimated in TRMM products. Moreover, heating associated with nonprecipitating shallow clouds could also be missed in TRMM-based estimates.

To further understand the physics responsible for the vertical tilt in MJO heating structure, contributions to 
(a) Q1

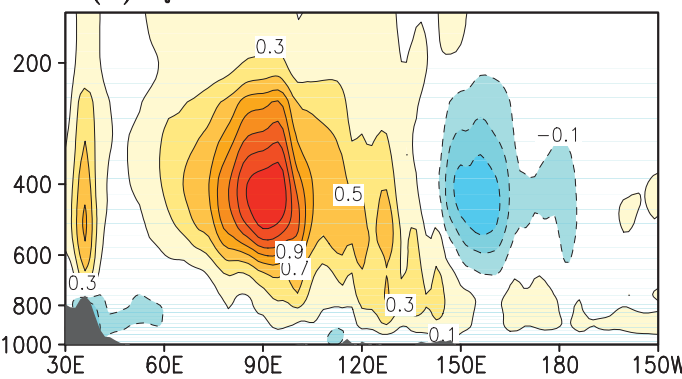

(c) Divergence

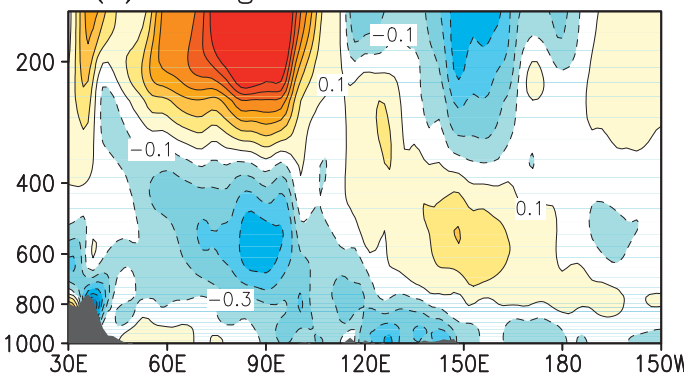

(e) Rainf all

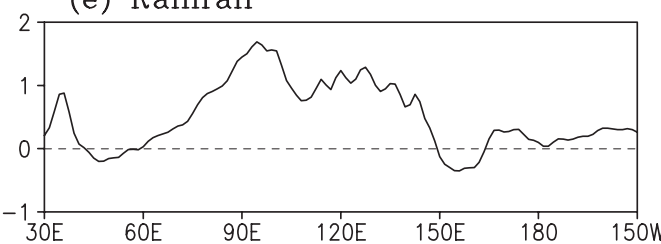

(b) Cloud Water

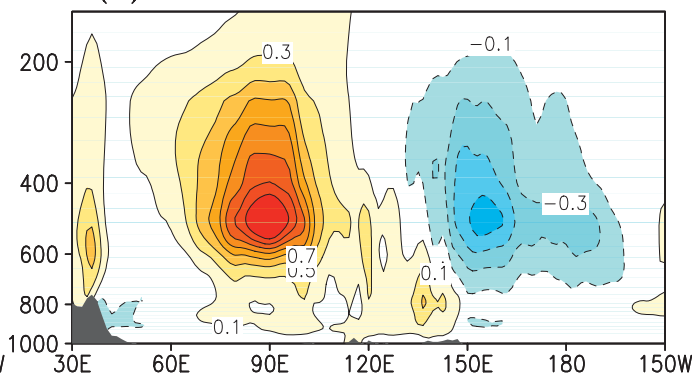

(d) Specific humidity

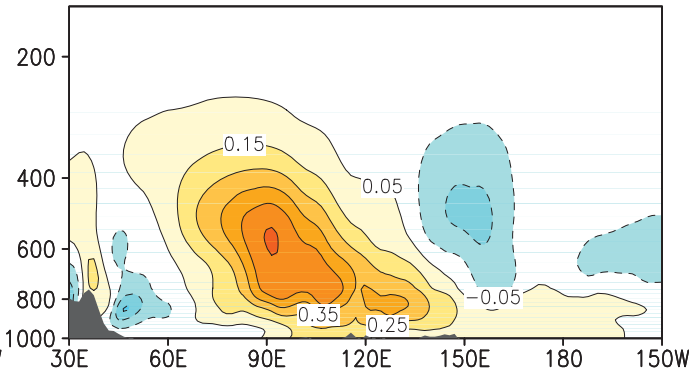

(f) Rainf all

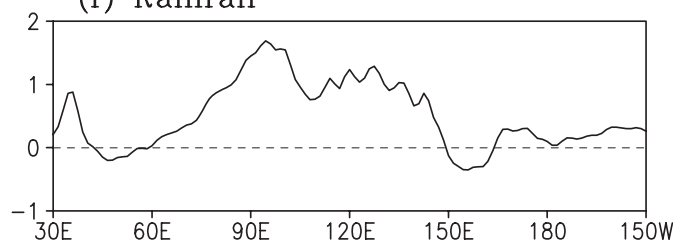

FIG. 5. Pressure-longitude cross sections of (a) anomalous heating $Q_{1}\left(\mathrm{~K} \mathrm{day}^{-1}\right)$; (b) cloud water $\left(10^{-5} \mathrm{~kg} \mathrm{~kg}^{-1}\right)$; (c) divergence $\left(10^{-6} \mathrm{~s}^{-1}\right)$; (d) specific humidity $\left(\mathrm{k} \mathrm{kg}^{-1}\right)$; and (e),(f) rainfall $\left(\mathrm{mm} \mathrm{day}^{-1}\right)$ at MJO phase 3. All variables are based on ERA-Interim and are averaged over $10^{\circ} \mathrm{S}-10^{\circ} \mathrm{N}$.

total $Q_{1}$ are further analyzed based on CFS-R output, because this is the only dataset that provides detailed output of various heating components, including the separation of latent heat release into convective and large-scale condensation forms. Pressure-time profiles of heating components by convection, large-scale condensation, radiation, and vertical diffusion are illustrated in Fig. 6 (shading) for both the WP and EEIO. The black curve in each panel is the total anomalous rainfall based on CFS-R. The green curve in Fig. 6b (Fig. 6g) represents the convective rainfall part, and the blue curve in Fig. $6 \mathrm{c}$ (Fig. 6h) represents rainfall due to large-scale condensation over the WP (EEIO). The result illustrates that both the total heating $Q_{1}$ and rainfall are dominated by the convective component in both regions. Over the WP, a heating maximum in total $Q_{1}$ around $900 \mathrm{hPa}$ ahead of the convection (e.g., phases 3 and 4 in Fig. 6a) is largely contributed by the convective heating component (Fig. 6b), as well as weak low-level cooling around phases 4 and 5 associated with the vertical dipole large-scale condensation component (Fig. 6c). Additionally, both the heating components by large-scale condensation (Fig. 6c) and radiation (Fig. 6d) lag the maximum convection in the mid-upper troposphere, which further contribute to the tilt in the total $Q_{1}$ profile. Similar features are generally found over the EEIO.

\section{b. Radiative heating profiles}

The vertical anomalous $Q_{R}$ structure in the associated with the MJO as shown by Fig. 6 over both the WP and EEIO is largely consistent with previous studies (e.g., Lin and Mapes 2004; Stephens et al. 2004); namely, positive $Q_{R}$ lags convection in the mid-upper troposphere, which could be associated with reduced radiative cooling due to residual high clouds after convection. Meanwhile, a negative $Q_{R}$ anomaly is evident during the clear sky period before the convection. This anomalous radiative cooling (heating) is thought to be important to destabilize/ stabilize the atmosphere before (after) the convection (Stephens et al. 2004). On the other hand, despite its relatively weaker amplitude compared to the convective heating, $Q_{R}$ is found to play an active role in MJO 

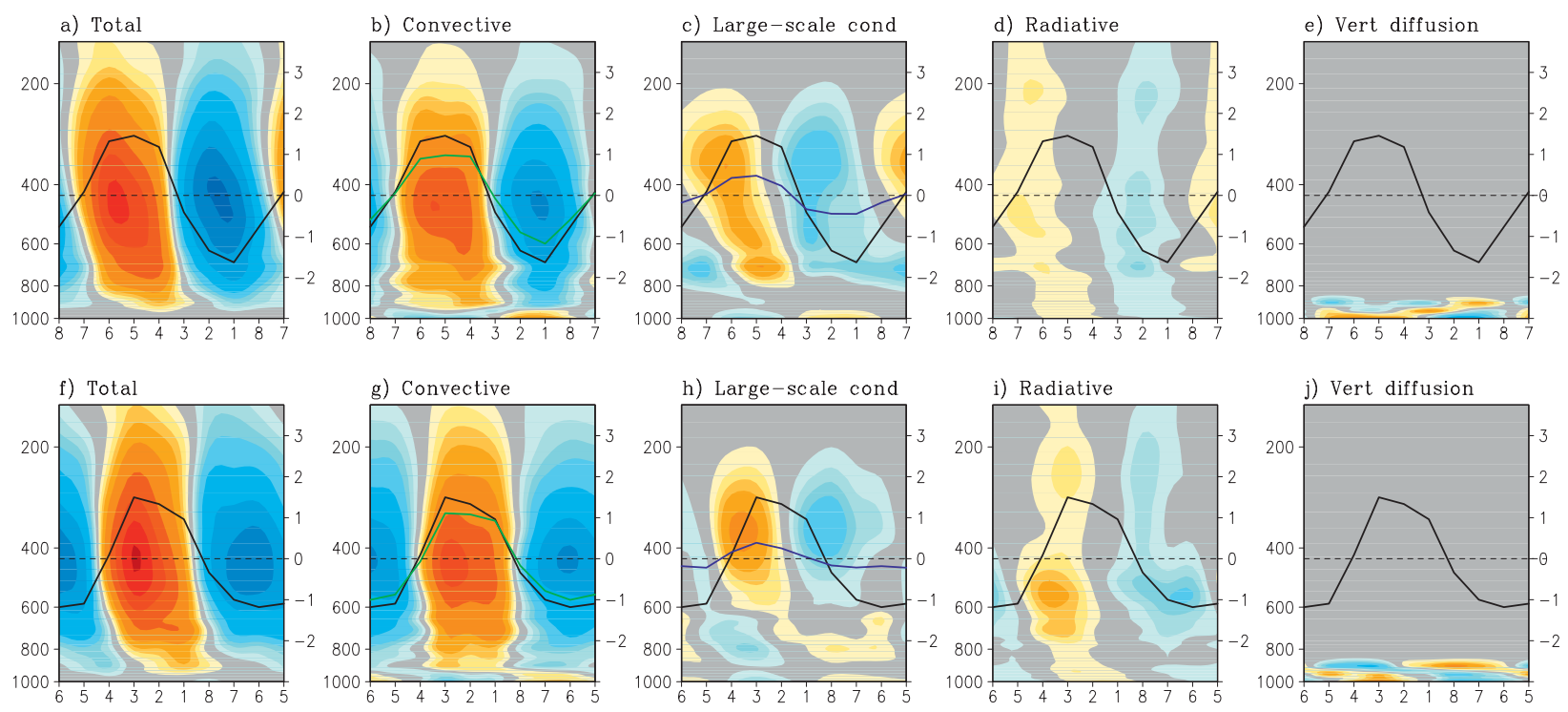

FIG. 6. Decomposition of total heating $Q_{1}$ (shaded; see color bar; units are K day ${ }^{-1}$ ) based on CFS-R model output for (a)-(c) the WP and (f)-(j) the EEIO. The black curve in each panel is the total rainfall profile based on the CFS-R for each region; green curves in Fig. $4 \mathrm{~b}$ (Fig. 4g) are convective rainfall component, and blue curves in Fig. 4c (Fig. 4h) are rainfall due to large-scale condensation over the WP (EEIO).

simulations based on several numerical studies (e.g., Lee et al. 2001; Raymond 2001; Sobel and Gildor 2003). Based on these studies, an enhancement factor of $Q_{R}$ for the MJO can be defined as a ratio between the columnintegrated $Q_{R}$ and the convective heating. It was suggested that "radiative-convective instability" for the MJO could emerge when this factor exceeds $20 \%$ (Lee et al. 2001; Raymond 2001; Lin and Mapes 2004).

Based on Fig. 6, the $Q_{R}$ associated with the MJO has a stronger amplitude over the EEIO than that over the WP. Calculations suggest enhancement factors of $28 \%$ over the EEIO ( 0.11 versus $0.36 \mathrm{~K}^{\text {day }}{ }^{-1}$ of vertically averaged radiative and convective heating between 1000 and $100 \mathrm{hPa}$; also see Fig. 8 for details) and $20 \%$ for the WP. Thus, this result may indicate the important role of $Q_{R}$ for the MJO, particularly over the EEIO, where very rapid intensification of the MJO is usually observed.

Figure 7 displays pressure-longitude profiles of $Q_{R}$ during the MJO evolution based on TRMM estimates as well as on MERRA and CFS-R, because $Q_{R}$ fields are only available from these three datasets. Results from all three datasets clearly illustrate the westward tilt in anomalous $Q_{R}$ associated with the MJO, although the tilt is relatively weak in TRMM. The maximum $Q_{R}$ signals appear at higher altitudes in TRMM and MERRA than those in CFS-R. Meanwhile, TRMM-based $Q_{R}$ shows stronger amplitude near the surface than those in the other two reanalyses. Weaker amplitudes in $Q_{R}$ near the surface in two reanalyses could be ascribed to more PBL clouds throughout all phases of the MJO in MERRA and CFS-R. This needs to be examined in greater detail that is beyond the scope of this present study. Consistent with results in Fig. 6, strongest MJO signals in $Q_{R}$ are found over the EEIO based on all three datasets. Note stronger $Q_{R}$ amplitudes in TRMM and MERRA datasets compared to CFS-R. This may suggest an even larger enhancement factor of $Q_{R}$ based on TRMM and MERRA versus CFS-R, as discussed above.

Figure 8 presents the vertically averaged convective (black) and radiative (gray) heating components over the WP (top panels) and EEIO (bottom panels) during the MJO life cycle based on the three datasets. Note that TRMM-based convective heating profiles in Figs. 8a,d are estimated by TRAIN $Q_{1}$ minus TRMM $Q_{R}$. The phase lag in the radiative heating to the convective heating is evident in all three datasets over both the EEIO and WP. This result is in agreement with previous studies (e.g., Lin and Mapes 2004). The enhancement factors can be roughly estimated based on each dataset over these two regions with corresponding maximum amplitudes of the convective heating and radiative heating components and are shown on the top-left corner of each panel. The calculation suggests enhancement factors as large as $40 \%$ over the EEIO based on TRMM estimates and $28 \%$ based on both MERRA and CFS-R, well exceeding the $20 \%$ threshold for radiative-convective instability, as 
TRMM

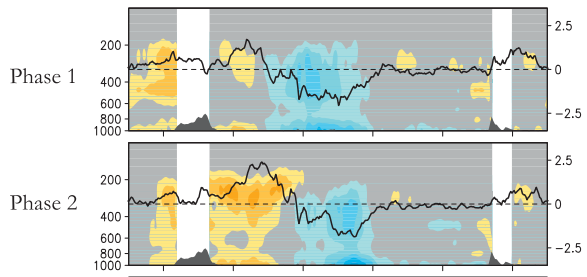

Phase 3
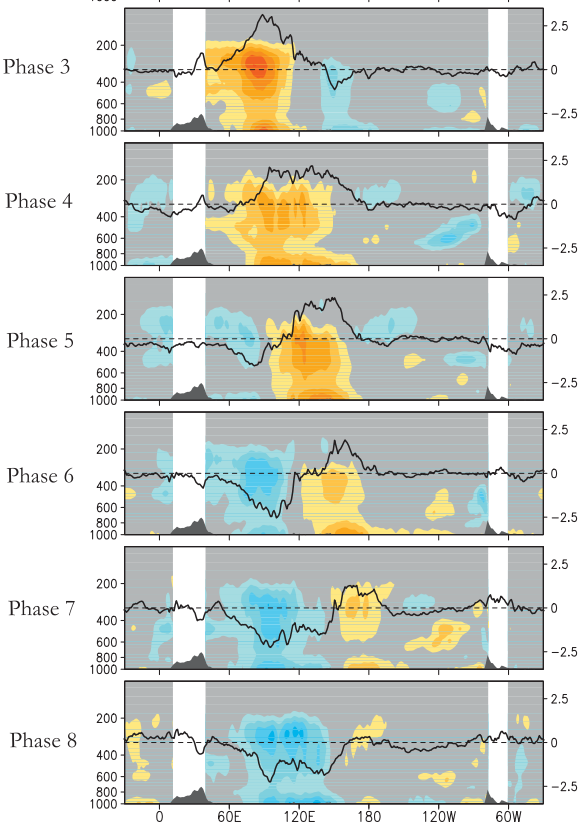

MERRA
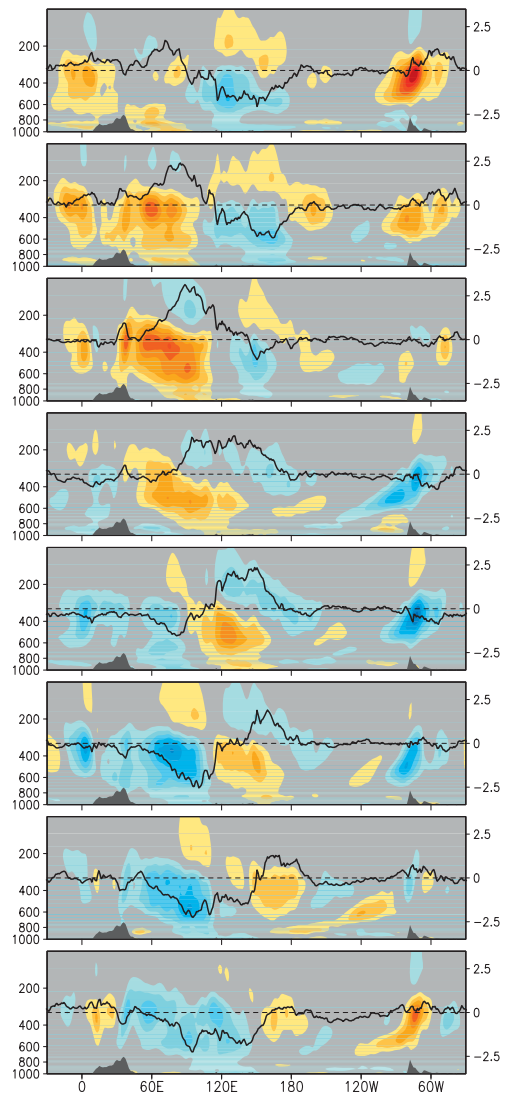

CFS $-\mathrm{R}$
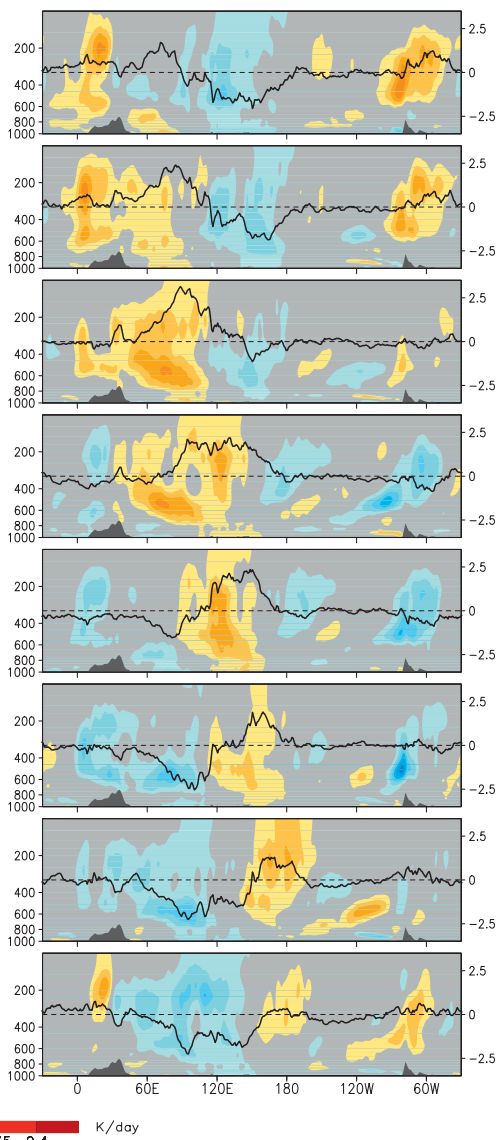

FIG. 7. As in Fig. 1, but for radiative heating structures based on (a) TRMM, (b) MERRA, and (c) CFS-R.

suggested by Lee et al. (2001). These factors are $18 \%$, $16 \%$, and $20 \%$ over the WP based on TRMM, MERRA, and CFS-R, respectively. The relatively larger enhancement factors over the Indian Ocean than the WP also largely agree with the results estimated by Lin and Mapes (2004) based on top-of-atmosphere (TOA) and surface radiative heating flux estimates. All these results indicate that the radiative heating may play an important role for the MJO instability over the Indian Ocean as suggested by Raymond (2001).

Finally, we conduct an extended empirical orthogonal function (EEOF) analysis of the TRMM $Q_{R}$ in order to confirm the MJO signals in radiative heating as shown in Fig. 7 based on composite analysis. Before the EEOF, daily vertical-longitudinal profiles of the 20-90-day bandpassfiltered TRMM $Q_{R}$ are calculated by averaging between $10^{\circ} \mathrm{S}$ and $10^{\circ} \mathrm{N}$ for the winters (November-April) of 1998-2007. Then these daily vertical-longitudinal $Q_{R}$ profiles during the 10 winters are binned into a 3-day mean and are subject to the EEOF analysis with 9 temporal lags. The first two leading EEOF modes, which are in quadrature to each other and thus reflect the same propagating mode, explain $18 \%$ of total bandpassfiltered $Q_{R}$ anomalies. Both the principal components of $\mathrm{EEOF}_{1}$ and $\mathrm{EEOF}_{2}$ exhibit a dominant period of about 40 days (figure not shown). The evolution of a vertical-longitudinal $Q_{R}$ profile captured by the $\mathrm{EEOF}_{1}$ is illustrated in Fig. 9 (shaded) with a time interval of every 6 days between the neighboring panels. The corresponding anomalous rainfall associated with the $Q_{R}$ profiles at each time are further reconstructed by regressing $\mathrm{PC}_{1}$ of $Q_{R}$ against bandpass-filtered rainfall fields during the same ten winters, and are displayed by the back curve in each panel of Fig. 9 (with right $y$ axis). A clear eastward propagation in both rainfall and $Q_{R}$ signals with a phase speed of $4-5 \mathrm{~m} \mathrm{~s}^{-1}$ is readily evident, again suggesting the $\mathrm{MJO}$ signals identified by the first leading EEOF mode of the $Q_{R}$ field. Meanwhile, slight vertical tilting structures in $Q_{R}$ as revealed in previous composite analysis is also captured by the $\mathrm{EEOF}_{1}$ of $Q_{R}$ : for example, the low-level radiative heating is largely in phase of convection, whereas $Q_{R}$ in the 
a) TRMM

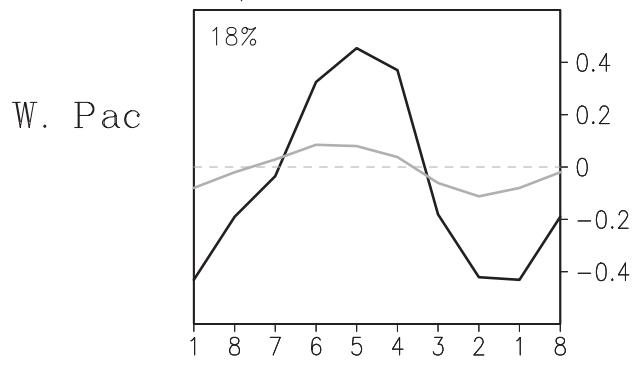

d) TRMM

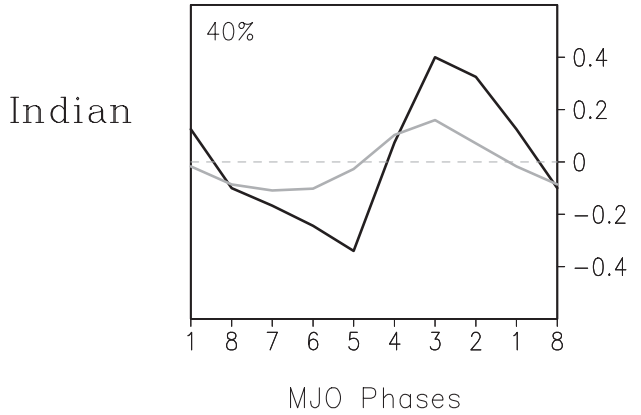

b) MERRA

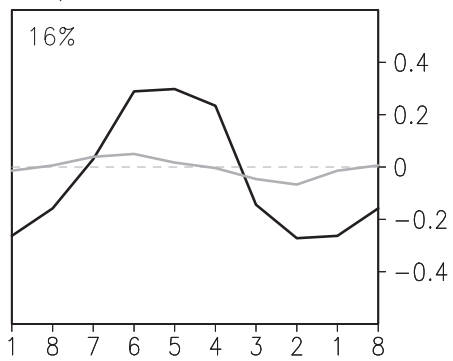

e) MERRA

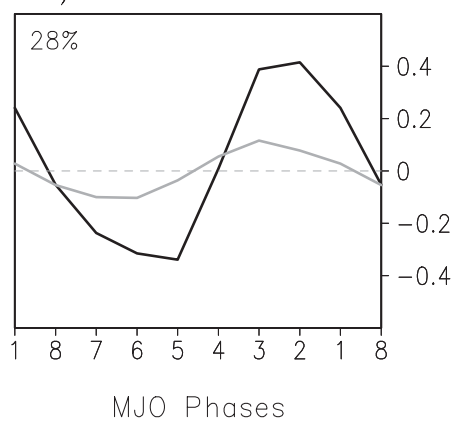

c) $\mathrm{CFS}-\mathrm{R}$

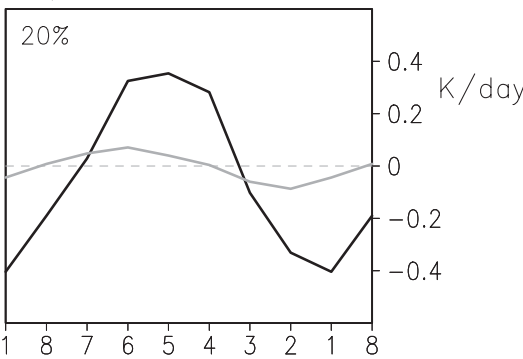

FIG. 8. Evolution of vertically averaged convective (black) and radiative (gray) heating between 1000 and 100 hPa as a function of MJO phase over the WP $\left(150^{\circ}-160^{\circ} \mathrm{E}\right)$ and the EEIO $\left(80^{\circ}-90^{\circ} \mathrm{E}\right)$ based on TRMM estimates, MERRA, and CFS-R reanalyses. All variables are averaged over $10^{\circ} \mathrm{S}-10^{\circ} \mathrm{N}$.

upper troposphere lags the maximum convection. All these results suggest the robustness of the $Q_{R}$ signals associated with the MJO.

\section{Summary}

Capitalizing on recently released reanalysis datasets and TRMM-based diabatic heating estimates, we have conducted a composite analysis of vertical heating structures associated with the MJO. Because diabatic heating lies at the heart of prevailing MJO theories, the intention of this effort is to provide new insights into the fundamental physics of the MJO. However, some discrepancies in the composite vertical MJO heating profiles are noted among the datasets, particularly between three reanalyses and three TRMM estimates. During its eastward propagation, westward tilting with altitude in the vertical heating structure of the MJO is clearly evident based on three reanalysis datasets, which is particularly pronounced when the MJO migrates from the EEIO to the WP. Namely, low-level heating first appears on the east side of the MJO convection, whereas heating in the upper troposphere lags the convection. In contrast, this vertical tilting heating structure is not readily detected in the three TRMM products. Moreover, a transition from a shallow to deep heating structure during the MJO evolution is also exhibited in a pressure-time plot over both the EEIO and WP based on three reanalysis datasets. Although this transition in vertical heating structure is also detectable based on TRMM CSH and SLH over the WP, it is weakly defined in TRAIN estimates. Meanwhile, all three TRMM datasets do not clearly capture the evolution from shallow to deep heating over the EEIO.

The vertical $Q_{R}$ profiles associated with the MJO are also analyzed based on TRMM estimates and two reanalyses, MERRA and CFS-R. A westward vertical tilt in $Q_{R}$ is apparent over all three datasets: that is, the lowlevel $Q_{R}$ is largely in phase with convection, whereas $Q_{R}$ in the upper troposphere lags the maximum convection. The role of $Q_{R}$ for MJO instability is further evaluated by an enhancement factor proposed by previous studies. An enhancement factor as large as $40 \%$ is noted over the Indian Ocean based on TRMM estimates, which well exceeds the $20 \%$ threshold for "radiative-convective instability," as suggested by Lee et al. (2001). This suggests a potentially important role of $Q_{R}$ for the MJO, particularly over the Indian Ocean, where the MJO experiences rapid intensification, as also discussed by Lin and Mapes (2004).

In interpreting the difference in the heating structures between reanalyses and TRMM products, it could be due to the uncertainties involved in these TRMM-based estimates. A diagnosis based on ERA-Interim suggests 


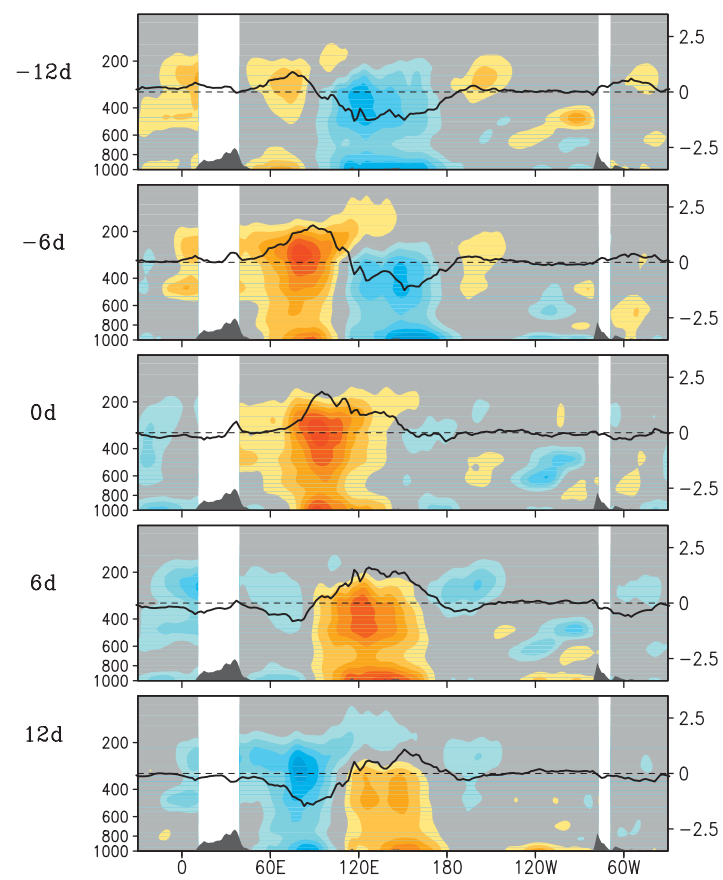

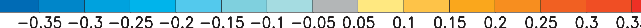

FIG. 9. Shading shows the evolution of the pressure-longitude $Q_{R}$ anomalies captured by the $\mathrm{EEOF}_{1}$ (see color bar below), and curves show the rainfall anomalies associated with $Q_{R}$ profiles derived by lag regression against the principal component of the $\mathrm{EEOF}_{1}$ (see right axis; units are $\mathrm{mm} \mathrm{day}^{-1}$ ). Time intervals between neighboring panels are 6 days.

that the low-level heating component ahead of the maximum MJO convection is accompanied by PBL convergence and enhanced moisture and cloud water in the lower troposphere; thus, it may represent a critical preconditioning process for the $\mathrm{MJO}$, as widely reported by many observational studies. It is expected that light rain from shallow clouds ahead of MJO deep convection could be underestimated because of reported TRMM deficiencies in detecting light rain and/or small, isolated rain events over regions where shallow clouds dominate (e.g., Short and Nakamura 2000; Berg et al. 2010). Heating associated with nonprecipitating shallow clouds could also be missed in TRMM-based estimates. Moreover, all three TRMM algorithms heavily depend on lookup tables generated by cloud-resolving models, which are further subject to parameterizations of microphysical processes.

On the other hand, despite relative consistency of diabatic heating among the reanalysis datasets, large uncertainties may exist in the model output, because the heating in the models is largely based on a subgrid cumulus parameterization component. It still remains a mystery whether the vertical tilt in heating structures as clearly evident in three reanalyses is essential for the MJO in reality, including its preconditioning and eastward propagation. It is also intriguing that the vertical transition in MJO heating from shallow to deep structures is most pronounced in the reanalyses when the MJO migrates from the EEIO to WP (e.g., phase 3 in Figs. 1 or 5). It may suggest that the topography over the Maritime Continent may also play a role in generating the shallow heating component to the east of the MJO.

Further investigation is needed to understand the differences in heating profiles between these datasets particularly in terms of cloud and water vapor structures. Comprehensive validations of these reanalyses and TRMM-based heating products against ground observations will be particularly valuable. For example, the forthcoming field campaign by the Dynamics of the Madden-Julian Oscillation (DYNAMO) program in the Indian Ocean will provide an excellent opportunity for validation of these heating profiles, as well as other physical processes associated with the MJO.

Regardless of the discrepancies in the MJO heating profiles between reanalyses and TRMM, an intercomparison of the heating structure associated with the MJO based on various products is especially valuable, because the TRMM-based diagnosis of heating vertical structure is still in its experimental phase. With continuous improvement of these TRMM-based heating algorithms, as well as improvement in rainfall observations such as the next-generation Global Precipitation Measurement (GPM) mission, a greater consistency would be expected among these TRMM-based estimates as well as between TRMM and reanalysis datasets.

Acknowledgments. We thank anonymous reviewers for their constructive comments on an earlier version of this manuscript. Thanks also to Terry Kubar for his comments and editorial assistance. The first author (XJ) acknowledges support by NSF Climate and Large-Scale Dynamics under Award ATM-0934285 and NOAA CPPA program under Award NA09OAR4310191. W. Olson and T. L'Ecuyer acknowledge support by NASA NEWS program. The Wheeler-Hendon MJO index was downloaded from the Australian BMRC website. We also thank Prof. B. Wang for insightful discussion. Part of this research was carried out at the Jet Propulsion Laboratory, California Institute of Technology, under a contract with the National Aeronautics and Space Administration.

\section{REFERENCES}

Benedict, J. J., and D. A. Randall, 2009: Structure of the MaddenJulian oscillation in the superparameterized CAM. J. Atmos. Sci., 66, 3277-3296. 
Berg, W., T. L'Ecuyer, and J. M. Haynes, 2010: The distribution of rainfall over oceans from spaceborne radars. J. Appl. Meteor. Climatol., 49, 535-543.

Bosilovich, M. G., and Coauthors, 2006: NASA's modern era retrospective-Analysis for research and applications. U.S. CLIVAR Variations, Vol. 4, U.S. CLIVAR Office, Washington, DC, 5-8.

Chan, S. C., and S. Nigam, 2009: Residual diagnosis of diabatic heating from ERA-40 and NCEP reanalyses: Intercomparisons with TRMM. J. Climate, 22, 414-428.

Chang, C.-P., and H. Lim, 1988: Kelvin wave-CISK: A possible mechanism for the 30-50 day oscillations. J. Atmos. Sci., 45, 1709-1720.

Chen, Y. H., and A. D. Del Genio, 2009: Evaluation of tropical cloud regimes in observations and a general circulation model. Climate Dyn., 32, 355-369, doi:10.1007/S00382-008-0386-6.

Elsaesser, G. S., C. D. Kummerow, T. S. L'Ecuyer, Y. N. Takayabu, and S. Shige, 2010: Observed self-similarity of precipitation regimes over the tropical oceans. J. Climate, 23, 2686-2698.

Fu, X. H., and B. Wang, 2009: Critical roles of the stratiform rainfall in sustaining the Madden-Julian oscillation: GCM experiments. J. Climate, 22, 3939-3959.

Grecu, M., and W. S. Olson, 2006: Bayesian estimation of precipitation from satellite passive microwave observations using combined radar-radiometer retrievals. J. Appl. Meteor. Climatol., 45, 416-433.

,-- C. L. Shie, T. S. L'Ecuyer, and W. K. Tao, 2009: Combining satellite microwave radiometer and radar observations to estimate atmospheric heating profiles. J. Climate, 22, 63566376.

Hagos, S., and Coauthors, 2010: Estimates of tropical diabatic heating profiles: Commonalities and uncertainties. J. Climate, 23, 542-558.

Hendon, H. H., and M. L. Salby, 1994: The life cycle of the MaddenJulian oscillation. J. Atmos. Sci., 51, 2225-2237.

Huffman, G. J., and Coauthors, 2007: The TRMM Multisatellite Precipitation Analysis (TMPA): Quasi-global, multiyear, combined-sensor precipitation estimates at fine scales. $J$. $H y$ drometeor., 8, 38-55.

Jiang, X., D. E. Waliser, M. C. Wheeler, C. Jones, M. N. Lee, and S. D. Schuert, 2008: Assessing the skill of an all-season statistical forecast model for the Madden-Julian oscillation. Mon. Wea. Rev., 136, 1940-1956.

— , and Coauthors, 2009: Vertical heating structures associated with the MJO as characterized by TRMM estimates, ECMWF reanalyses, and forecasts: A case study during 1998/99 winter. J. Climate, 22, 6001-6020.

Johnson, R. H., T. M. Rickenbach, S. A. Rutledge, P. E. Ciesielski, and W. H. Schubert, 1999: Trimodal characteristics of tropical convection. J. Climate, 12, 2397-2418.

Katsumata, M., R. H. Johnson, and P. E. Ciesielski, 2009: Observed synoptic-scale variability during the developing phase of an ISO over the Indian Ocean during MISMO. J. Atmos. Sci., 66, 3434-3448.

Kemball-Cook, S. R., and B. C. Weare, 2001: The onset of convection in the Madden-Julian oscillation. J. Climate, 14, 780-793.

Khouider, B., and A. J. Majda, 2008: Multicloud models for organized tropical convection: Enhanced congestus heating. J. Atmos. Sci., 65, 895-914.

Kikuchi, K., and Y. N. Takayabu, 2004: The development of organized convection associated with the MJO during TOGA COARE IOP: Trimodal characteristics. Geophys. Res. Lett., 31, L10101, doi:10.1029/2004GL019601.
Kiladis, G. N., K. H. Straub, and P. T. Haertel, 2005: Zonal and vertical structure of the Madden-Julian oscillation. J. Atmos. Sci., 62, 2790-2809.

Kim, D., and Coauthors, 2009: Application of MJO simulation diagnostics to climate models. J. Climate, 22, 6413-6436.

Lau, K.-M., and L. Peng, 1987: Origin of low-frequency (intraseasonal) oscillations in the tropical atmosphere. Part I: Basic theory. J. Atmos. Sci., 44, 950-972.

_ , and D. E. Waliser, 2005: Intraseasonal Variability in the Atmosphere-Ocean Climate System. Springer, 474 pp.

, and H.-T. Wu, 2010: Characteristics of precipitation, cloud, and latent heating associated with the Madden-Julian oscillation. J. Climate, 23, 504-518.

L'Ecuyer, T. S., and G. L. Stephens, 2003: The tropical oceanic energy budget from the TRMM perspective. Part I: Algorithm and uncertainties. J. Climate, 16, 1967-1985.

— and - 2007: The tropical atmospheric energy budget from the TRMM perspective. Part II: Evaluating GCM representations of the sensitivity of regional energy and water cycles to the 1998-99 ENSO cycle. J. Climate, 20, 4548-4571.

— radiative heating and its vertical structure from TRMM observations. J. Climate, 23, 519-541.

Lee, M. I., I. S. Kang, J. K. Kim, and B. E. Mapes, 2001: Influence of cloud-radiation interaction on simulating tropical intraseasonal oscillation with an atmospheric general circulation model. J. Geophys. Res., 106, 14 219-14 233.

Li, C., X. Jia, J. Ling, W. Zhou, and C. Zhang, 2009: Sensitivity of MJO simulations to diabatic heating profiles. Climate Dyn., 32, 167-187, doi:10.1007/S00382-008-0455-X.

Lin, J.-L., and B. E. Mapes, 2004: Radiation budget of the tropical intraseasonal oscillation. J. Atmos. Sci., 61, 2050-2062.

- - — M. Zhang, and M. Newman, 2004: Stratiform precipitation, vertical heating profiles, and the Madden-Julian oscillation. J. Atmos. Sci., 61, 296-309.

— , and Coauthors, 2006: Tropical intraseasonal variability in 14 IPCC AR4 climate models. Part I: Convective signals. J. Climate, 19, 2665-2690.

Ling, J., and C. Zhang, 2011: Structural evolution in heating profiles of the MJO in global reanalyses and TRMM retrievals. J. Climate, 24, 825-842.

Madden, R. A., and P. R. Julian, 1971: Detection of a 40-50 day oscillation in zonal wind in tropical Pacific. J. Atmos. Sci., 28, $702-708$.

- and - 1994: Observations of the 40-50-day tropical oscillation: A review. Mon. Wea. Rev., 122, 814-837.

Maloney, E. D., and D. L. Hartmann, 1998: Frictional moisture convergence in a composite life cycle of the Madden-Julian oscillation. J. Climate, 11, 2387-2403.

Mapes, B. E., 2000: Convective inhibition, subgrid-scale triggering energy, and stratiform instability in a toy tropical wave model. J. Atmos. Sci., 57, 1515-1535.

—, S. Tulich, J. Lin, and P. Zuidema, 2006: The mesoscale convection life cycle: Building block or prototype for large-scale tropical waves? Dyn. Atmos. Oceans, 42, 3-29, doi:10.1016/ j.dynatmoce.2006.03.003.

Masunaga, H., T. S. L'Ecuyer, and C. D. Kummerow, 2005 Variability in the characteristics of precipitation systems in the tropical Pacific. Part I: Spatial structure. J. Climate, 18, 823-840.

Morita, J., Y. N. Takayabu, S. Shige, and Y. Kodama, 2006: Analysis of rainfall characteristics of the Madden-Julian oscillation using TRMM satellite data. Dyn. Atmos. Oceans, 42, 107-126. 
Raymond, D. J., 2001: A new model of the Madden-Julian oscillation. J. Atmos. Sci., 58, 2807-2819.

Saha, S., and Coauthors, 2010: The NCEP Climate Forecast System Reanalysis. Bull. Amer. Meteor. Soc., 91, 1015-1057.

Seo, K. H., and W. Q. Wang, 2010: The Madden-Julian oscillation simulated in the NCEP Climate Forecast System model: The importance of stratiform heating. J. Climate, 23, 4770-4793.

Shige, S., Y. N. Takayabu, W.-K. Tao, and D. E. Johnson, 2004: Spectral retrieval of latent heating profiles from TRMM PR data. Part I: Development of a model-based algorithm. J. Appl. Meteor., 43, 1095-1113.

,,--- , and C. L. Shie, 2007: Spectral retrieval of latent heating profiles from TRMM PR data. Part II: Algorithm improvement and heating estimates over tropical ocean regions. J. Appl. Meteor. Climatol., 46, 1098-1124.

- — - and - 2008: Spectral retrieval of latent heating profiles from TRMM PR data. Part III: Estimating apparent moisture sink profiles over tropical oceans. J. Appl. Meteor. Climatol., 47, 620-640.

,-- , S. Kida, W. K. Tao, X. P. Zeng, C. Yokoyama, and T. L'Ecuyer, 2009: Spectral retrieval of latent heating profiles from TRMM PR data. Part IV: Comparisons of lookup tables from two- and three-dimensional cloud-resolving model simulations. J. Climate, 22, 5577-5594.

Short, D. A., and K. Nakamura, 2000: TRMM radar observations of shallow precipitation over the tropical oceans. J. Climate, 13, 4107-4124.

Simmons, A., S. Uppala, D. Dee, and S. Kobayashi, 2006: ERAInterim: New ECMWF reanalysis products from 1989 onwards. ECMWF Newsletter, No. 110, ECMWF, Reading, United Kingdom, 25-35.

Slingo, J. M., and Coauthors, 1996: Intraseasonal oscillations in 15 atmospheric general circulation models: Results from an AMIP diagnostic subproject. Climate Dyn., 12, 325-357.

—, P. M. Inness, and K. R. Sperber, 2005: Modeling. Intraseasonal Variability in the Atmosphere-Ocean Climate System, W. K. M. Lau and D. E. Waliser, Eds., Springer, 361-388.

Sobel, A. H., and H. Gildor, 2003: A simple time-dependent model of SST hot spots. J. Climate, 16, 3978-3992.

Sperber, K. R., 2003: Propagation and the vertical structure of the Madden-Julian oscillation. Mon. Wea. Rev., 131, 3018-3037.

Stephens, G. L., P. J. Webster, R. H. Johnson, R. Engelen, and T. L'Ecuyer, 2004: Observational evidence for the mutual regulation of the tropical hydrological cycle and tropical sea surface temperatures. J. Climate, 17, 2213-2224.

Takayabu, Y. N., S. Shige, W. K. Tao, and N. Hirota, 2010: Shallow and deep latent heating modes over tropical oceans observed with TRMM PR spectral latent heating data. J. Climate, 23, 2030-2046.

Tao, W.-K., and Coauthors, 2006: Retrieval of latent heating from TRMM measurements. Bull. Amer. Meteor. Soc., 87, 1555-1572.
— S. Lang, X. Zeng, S. Shige, and Y. Takayabu, 2010: Relating convective and stratiform rain to latent heating. J. Climate, 23, 1874-1893.

Tian, B., D. E. Waliser, E. J. Fetzer, B. H. Lambrigtsen, Y. L. Yung, and B. Wang, 2006: Vertical moist thermodynamic structure and spatial-temporal evolution of the MJO in AIRS observations. J. Atmos. Sci., 63, 2462-2485.

- — - — , and Y. L. Yung, 2010: Vertical moist thermodynamic structure of the Madden-Julian oscillation in atmospheric infrared sounder retrievals: An update and a comparison to ECMWF Interim Re-Analysis. Mon. Wea. Rev., 138, 4576-4582.

Tromeur, E., and W. B. Rossow, 2010: Interaction of tropical deep convection with the large-scale circulation in the MJO. J. Climate, 23, 1837-1853.

Waliser, D. E., 2006: Predictability of tropical intraseasonal variability. Predictability of Weather and Climate, T. Palmer and R. Hagedorn, Eds., Cambridge University Press, 275-305. , and Coauthors, 2006: The Experimental MJO Prediction Project. Bull. Amer. Meteor. Soc., 87, 425-431.

Wang, B., 2005: Theories. Intraseasonal Variability in the AtmosphereOcean Climate System, W. K. M. Lau and D. E. Waliser, Eds., Springer, 389-424.

— , and H. Rui, 1990: Dynamics of the coupled moist KelvinRossby wave on an equatorial $\beta$-plane. J. Atmos. Sci., 47, 397-413.

Webster, P. J., and R. Lukas, 1992: TOGA COARE-The Coupled Ocean Atmosphere Response Experiment. Bull. Amer. Meteor. Soc., 73, 1377-1416.

Wheeler, M. C., and H. H. Hendon, 2004: An all-season realtime multivariate MJO index: Development of an index for monitoring and prediction. Mon. Wea. Rev., 132, 19171932.

Wu, Z. H., 2003: A shallow CISK, deep equilibrium mechanism for the interaction between large-scale convection and large-scale circulations in the tropics. J. Atmos. Sci., 60, 377-392.

Yanai, M., S. Esbensen, and J.-H. Chu, 1973: Determination of bulk properties of tropical cloud clusters from large-scale heat and moisture budgets. J. Atmos. Sci., 30, 611-627.

Zhang, C., 2005: Madden-Julian oscillation. Rev. Geophys., 43, RG2003, doi:10.1029/2004RG000158.

_ and Coauthors, 2010: MJO signals in latent heating: Results from TRMM retrievals. J. Atmos. Sci., 67, 3488-3508.

Zhang, G. J., and M. Mu, 2005: Effects of modifications to the Zhang-McFarlane convection parameterization on the simulation of the tropical precipitation in the National Center for Atmospheric Research Community Climate Model, version 3. J. Geophys. Res., 110, D09109, doi:10.1029/2004JD005617.

_, and X. Song, 2009: Interaction of deep and shallow convection is key to Madden-Julian oscillation simulation. Geophys. Res. Lett., 36, L09708, doi:10.1029/2009GL037340. 